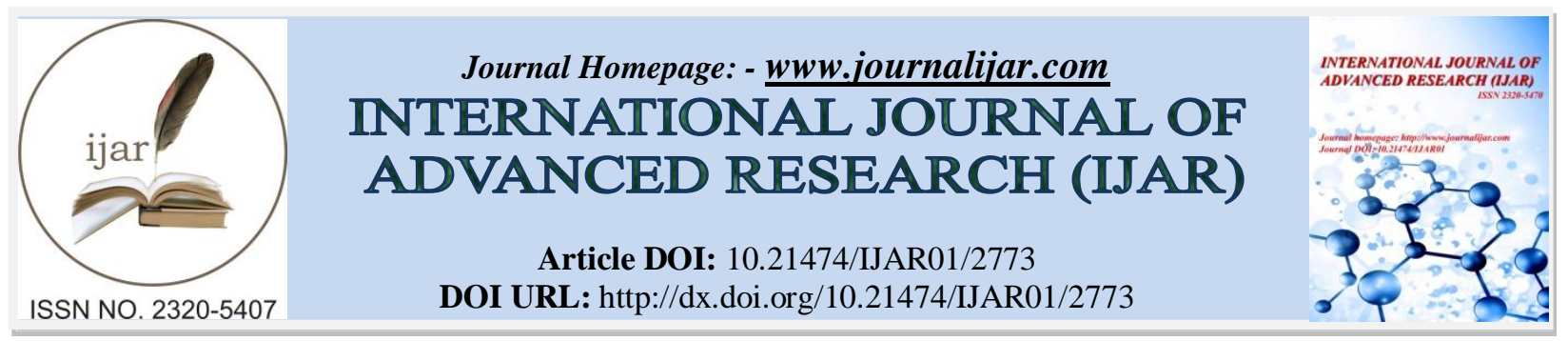

RESEARCH ARTICLE

\title{
10 YEARS PREVALENCE OF HEPATITIS B INFECTION AMONG WOMEN DELIVERING AT KAMC- JEDDAH AND THEIR INFANTS.
}

Taghreed Shams, Aishah Saeed Alasmari, Daniyah Hassan Saleh and Hawazin Abdul Rahman Fallatah.

\section{Manuscript Info}

(.........................

Manuscript History

Received: 15 November 2016

Final Accepted: 17 December 2016

Published: January 2017
Abstract

Copy Right, IJAR, 2016,. All rights reserved.

\section{Introduction:-}

Hepatitis B infection is a common infectious disease worldwide. There are nearly 2 billion people with hepatitis B infection throughout the world. About one million people die yearly from its complications(1).In Saudi Arabia, the ministry of health considers hepatitis B virus infection as second most common viral disease after chickenpox with almost 4700 new cases diagnosed annually(2).

Hepatitis B is an inflammation of the liver caused by specific type of virus called B virus, interaction of the virus and host immunity lead to liver injury which may be complicated by cirrhosis and hepatocellular carcinoma (HCC). HBV is transmitted through infected body fluid such as blood, semen and vaginal secretions. IV drug users, infected sexual contact, infant born to infected mothers are all at risk of development of the infection. Infected individual can be symptomatic or asymptomatic(3).

Mother-to-child transmission, is one of the most important cause of HBV carriers(4), that's why recommended to screen all pregnant ladies for $\mathrm{HBsAg}$ in the first antenatal visit specially in endemic areas (e.g. Saudi Arabia).Infection with hepatitis B in newborns of carrier mothers is the leading cause of development of chronicity state up to $80 \%$ of the disease, Interrupting of HBV transmission through administration a highly effective neonatal immune-prophylaxis by vaccination and intra-venous immunoglobulin (IVIG) in the first 24 hours of life has a major impact in reducing the prevalence of cases. Despite immune-prophylaxis there are still documented cases of vertical transmission of HBV(5). In study conducted in china (2014), Vertical transmission rate has been reported around $(5.44 \%)$ of infants despite immune-prophylaxis. they recommended further studies should work on prevention of immune-prophylaxis failure. Several studies implied that Mothers with positive HBeAg, high maternal viral load and positive cord blood for HBV DNA are most important factors that contributed to immune-prophylaxis failure(6).

Other studies shows a correlation between risk factors such as mode of delivery, ante-partum complications, procedures, intra-partum intervention and HBV vertical transmission(7).

Corresponding Author:- Taghreed Shams. 
The aim of study is to measure SCRENNING RATES of mother and their infants for HBV and the failure rate immune-prophylaxis in preventing vertical transmission of HBV at King Abdul-Aziz Medical City, National Guard Hospital Affairs (KAMC, NGHA).

\section{The Research Problem:-}

To screening rates for mother and their infants for HBV and to measure failure rate of immune-prophylaxis in preventing vertical transmission of HBV at King Abdul-Aziz Medical City, National Guard Hospital Affairs (KAMC, NGHA).in the period between 2005-2014.

\section{Research objectives:-}

- To Identify screening rate of HbsAg of mothers and their infants.

- To Estimate the incidence of vertical transmission of HBV in infants of HBV carrier mothers.

- To countthe incidence of HBV carrier state in pregnant women at KAMC in the period between 2005-2014.

- To correlate risk factors for failure of HBV immune-prophylaxis.

\section{Research Methodology:-}

This retrospective cross-sectional study was conducted at KAMC between Sep 2009 until Dec 2014. Medical records of all pregnant women with positive HBsAg and their infants were collected and reviewed. Maternal Demographic data, hepatitis serology, liver function test, antepartum procedures and duration of rupture of fatal membrane, mode of delivery, and perennial tears were collected. Infant timing of initial HBV vaccination and administration of IVIG, subsequent HBV vaccination, and screening were collected.

The primary outcome was the screening rate of HbsAg in infant HBV among pregnant women delivering in KAMCJeddah.

The secondary outcomes were failure of infant immune-prophylaxis to achieve positive HBsAb at age of 6-12 moths, and rate vertical transmission of HBV from carrier mothers to their infant's defined as HBsAg positive at age 6-12 moths. All Data was managed by SPSS version 21.

\section{Results and Discussion:-}

This study its the first done in Saudi Arabia that addresses an health issue with a significant burden of disease hopping in results can help in primary prevention of HBV infection. Although Saudi Arabia is one of endemic area of hepatitis B but still ante-natal screening for mothers is low about for many reasons such as decrease awareness about HB infection among health care providers and society. Even after mothers being HBsAg positive after screening only about $38.18 \%$ of these infants was screened for HBV for many reasons such as maternal poor compliance, no booked appointment and emergent delivery cases. Which its despite recommendation against invasive interventional of mothers with infectious diseases (8).

Among 23,756 deliveries in the period between 2005-2014, 152 women with positive HBsAg were identified. Those women gave birth to 251 children during study period. Only $16.7 \%(42 / 251)$ of infants were screened, none was found to have HBsAg.

$7 \%$ of all children (18/251) were screening between age of 2-6 years. Only one child was found to have $\mathrm{HbsAg}$ positive at age of 5 year. Among screened children, 20\% (14/60) were found to be susceptible at time of screening. $23.9 \%(60 / 251)$ of children had antenatal invasive testing. 60 of them had done Fetal scalp electrode andwith Chorionic villous sampling. 14 of them had $\mathrm{HbeAg}(9 \%)$ and $54 \%$ had abnormal liver function test. The mean age of screened mother found 31.17 years, with gestational age mean of delivery 38.99 weeks.

All 251 children that delivered were documented receivedfirstdose vaccine and 199 (79\%) of them found to had IVIG within the first 24 hours after delivery.

In pervious studies suggested the role of caesarian deliveries to achieve a better outcome in decreasing rate of vertical transmission by minimize the direct contact between mother and fetus in compare with vaginal deliveries (7). 
One of changes dealt through conducting the study HBV It is relatively rare disease. Retrospective nature that relies on documentation and limited access all medical records due to lack of computerized health information system before 2009. A lot of infant got immunized in other health care facilities other than KAMC.

Table 1:- The rate of HBV screening among infant of HBV infected mothers

\begin{tabular}{|l|l|l|l|}
\hline Rate of screening & & & \\
\hline screened & 60 & $\begin{array}{l}23.9 \% \text { of all HBV } \\
\text { mothers }\end{array}$ & \\
\hline & & & \\
\hline First year & 44 & $70 \%$ & \\
\hline Second & 8 & $3.18 \%$ & \\
\hline Third & 2 & $0.79 \%$ & \\
\hline Forth & 1 & $0.39 \%$ & \\
\hline Fifth & 2 & $0.79 \%$ & \\
\hline Sixth & 3 & $1.19 \%$ & \\
\hline
\end{tabular}

Figuer: Intra-partum risk factors

of total 251

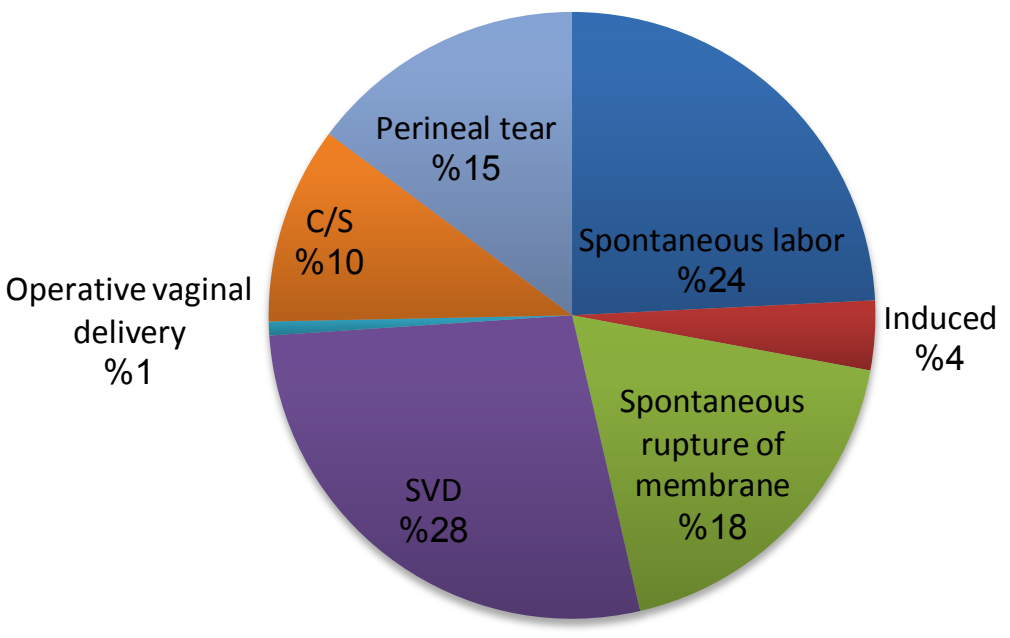

Figure 1:- Intra-partum risk factors of total 251 deliveries.

\section{Conclusion:-}

Screening rates of HbsAg of 251 (38.18\%)for infants and (23.9\%) for of total 152 women whom found with positive HBsAg period between 2005-2014 whom delivered in KAMC, NGHA. 70\% of them during first year of infancy.

All 251 about $38.18 \%$ of these infants and children that delivered were documented received firstdose vaccine and 199 (79\%) of them found to had IVIG within the first 24 hours after delivery. 
There were an observed decreased numbers of maternal and infant screening rates for HBV. A Further studies are needed to determine the risk factors associated with failed immune-prophylaxis.

\section{Acknowledgment:-}

We would like to express our Acknowledgment

Dr. Taghreed Shams(Consultant General Obstetrics \& Gynecology) for her strong support and guidance and Dr. Hashem AlHashemi Consultant Physical Rehabilitation Medicine (MNGHA, KAMC-WR) for statistical analysis support.

\section{Perspectives:-}

Educating health care worker regarding the WHO recommendation for prevention of HBV vertical transmission. Institute a strong policy regarding screening and follow up for infant of HBV infected mother Educating the HBV infected mothers regarding the importance of infant screening. We will calculate the rate of HBV screening among pregnant women.

\section{References:-}

1. André F. Hepatitis B epidemiology in Asia, the middle East and Africa. Vaccine. 2000;18:S20-S2.

2. Abdo AA, Sanai FM, Al-Faleh FZ. Epidemiology of viral hepatitis in Saudi Arabia: Are we off the hook? Saudi journal of gastroenterology: official journal of the Saudi Gastroenterology Association. 2012;18(6):349.

3. Mast EE, Margolis HS, Fiore AE, Brink EW, Goldstein ST, Wang SA, et al. A comprehensive immunization strategy to eliminate transmission of hepatitis B virus infection in the United States. MMWR. 2005;54(16):1-32.

4. Wiseman E, Fraser MA, Holden S, Glass A, Kidson BL, Heron LG, et al. Perinatal transmission of hepatitis B virus: an Australian experience. Medical Journal of Australia. 2009;190(9):489.

5. Godbole G, Irish D, Basarab M, Mahungu T, Fox-Lewis A, Thorne C, et al. Management of hepatitis B in pregnant women and infants: a multicentre audit from four London hospitals. BMC pregnancy and childbirth. 2013;13(1):222.

6. Lin X, Guo Y, Zhou A, Zhang Y, Cao J, Yang M, et al. Immunoprophylaxis Failure Against Vertical Transmission of Hepatitis B Virus in the Chinese Population: A Hospital-based Study and a Meta-analysis. The Pediatric infectious disease journal. 2014;33(9):897-903.

7. Guo Z, Shi X, Feng Y, Wang B, Feng L, Wang S, et al. Risk factors of HBV intrauterine transmission among HBsAg-positive pregnant women. Journal of viral hepatitis. 2013;20(5):317-21.

8. Giles ML1, Grace R, Tai A, Michalak K, Walker SP.Prevention of mother-to-child transmission of hepatitis B virus (HBV) during pregnancy and the puerperium: current standards of care.2013 Jun;53(3):231-5. 